\title{
Assessment of the release program of the European Roe Deer Capreolus capreolus (Cetartiodactyla: Cervidae) at Ajloun Nature Reserve, Jordan
}

\author{
Ehab Khalil Eid ${ }^{1} \&$ Yaseen Ananbeh ${ }^{2}$ \\ 1,2 The Royal Society for the Conservation of Nature, P. O. Box 1215, Al Jubeiha, 11941 Jordan \\ Email: ehab@rscn.org.jo, eha_jo@yahoo.com ${ }^{1}$
}

Date of online publication 26 June 2009 ISSN 0974-7907 (online) | 0974-7893 (print)

Editor: Pritpal Soorae

\section{Manuscript details:}

Ms \# 02103

Received 04 December 2008

Final received 13 May 2009

Finally accepted 08 June 2009

Citation: Eid, E.K. \& Y. Ananbeh (2009). Assessment of the release program of the European Roe Deer Capreolus capreolus (Cetartiodactyla: Cervidae) at Ajloun Nature Reserve, Jordan. Journal of Threatened Taxa 1(6): 323-326.

Copyright: (c) Ehab Khalil Eid \& Yaseen Ananbeh 2009. Creative Commons Attribution 3.0 Unported License. JoTT allows unrestricted use of this article in any medium for nonprofit purposes, reproduction and distribution by providing adequate credit to the authors and the source of publication.

Author Contribution: Both have equal contribution in the fieldwork preparation and data collecting. In addition, EKE has prepared this manuscript.

Acknowledgements: The authors are grateful to the Royal Society for the Conservation of Nature (RSCN) represented by its General Director Mr. Yahia Khalid, Mr. Mohammad Yousef, Conservation Director; Mr. Naser Abasi, Ajloun Nature Reserve Manager; and Enas Sakkejjha, Research and Survey Head Section for their continuous help and support. Gratitude's are extended to Mrs. Natalia Boulad and Mrs. Yasmine Hajeer, GIS and database officers, RSCN for preparing the required map. Thanks are extended to all people who contributed to the release program at Ajloun Nature Reserve. Finally, this paper is extended to the memory of Mr. Mohammad Khatatbeh, who had participated in the program since its inception and until end and had a major role in its success.
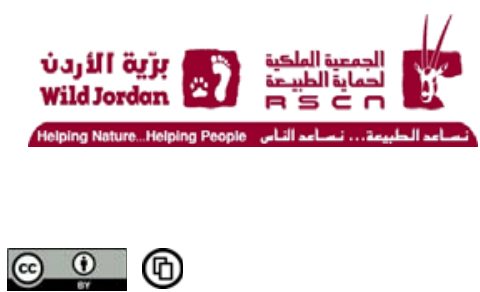

OPEN ACCESS | FREE DOWNLOAD
Abstract: Abstract: The release program of European Roe Deer Capreolus capreolus was launched in 1989 when the Royal Society for the Conservation of Nature (RSCN) received a donation of four individuals (two males and two females) from Turkish-Bulgarian border. The aim of the program was to establish a viable population in the former habitat of the species. The program was ongoing for almost 18 years at Ajloun Forest Reserve. On 19 January 2006, 26 individuals (11 males and 15 females) were released in the reserve. After collecting information relating to the breeding and release program, a rapid assessment survey was conducted during August and September 2007. Based on visual census, spoor routes, opportunistic observations and interviews method, a distribution map was produced and it was found that the released population had dispersed inside the reserve. Occasionally, they were found to have wandered outside the reserve, where they used surrounding vineyards for feeding and resting; a total of four individuals of two males and two females were counted. The RSCN has succeeded in establishing a free viable population, in its natural habitat, using effective long-term on-site management. It would be recommendable to establish a socio-economic program, and ongoing outreach programs in order to raise the awareness of the importance of protecting endangered species, and secure continuous funding. a further recommendation would be to provide training in deer management for the ecologist and further staff on the reserve and to implement a monitoring program for the released herd in order to insure the success of the reintroduction program.

Keywords: Ajloun Nature Reserve, European Roe Deer, Jordan, Re-introduction, RSCN.

\section{INTRODUCTION}

The European Roe Deer Capreolus capreolus occurs in the Palaearctic region from Britain to the Iberian Peninsula, Scandinavia, Poland, Western former USSR countries, Siberia east to the Sea of Japan, Manchuria, parts of China and Korea. It is also found in Transcaucasia, Asia Minor and Iran (Harrison et al. 1991). In Arabia, it was found in the forested mountainous ranges of the northern part of the region. Hatt (1959) considered it to be very rare in Iraq and noted that Reed (in litt., 1954) found them surviving on Harir Dagh and in the mountains round Mergasor. In Syria, it occurred in the bush-clad hills west of Allepo (Carruthers 1909) and in the mountains east of Latakia (Talbot 1906). Tristram (1866) found it in the bare hilly country between Tyre and Lake Galilee (Carruthers 1909). It seems reasonable to assume that it has now completely disappeared from most, if not all, of its former range in Arabia (Harrison \& Bates 1991).

European Roe Deer inhabited the forested regions in northern Jordan valley and in the hills of northern Palestine (Carruthers 1909). It, most probably, disappeared from Jordan at the beginning of the $19^{\text {th }}$ century (Amr 2000). Harrison (1968) state that the most important reason for its declining numbers was deforestation. Harrison \& Bates (1991) indicate that the virtual extinction of the Roe Deer from Arabia is in part due to increased hunting pressure and in part to the deforestation in its former habitat.

During 1989, The Royal Society for the Conservation of Nature (RSCN) received four individuals of Roe Deer (two males and two females) from the Turkish-Bulgarian border as a donation. The captive breeding program starts in $0.02 \mathrm{~km}^{2}$ enclosure at the Zubiya Nature Reserve. In August 2000, 14 individuals of equal numbers of males and females were transferred to Ajloun Forest Reserve (ANR) which has the same vegetation type as Zubiya Reserve. Only nine individuals (five males and four females) survived and were placed into a $0.01 \mathrm{~km}^{2}$ breeding enclosure. During the breeding program, 2540 liters of water were supplied to the herd daily (around 1.65-2.65/animal). In addition; $50 \mathrm{~kg}$ of feed was supplied daily $(3,4 \mathrm{~kg} /$ animal) $25 \mathrm{~kg}$ at dawn and $25 \mathrm{~kg}$ in the evening.

The program at Ajloun Forest Reserve lasted almost 18 years and was aimed at establishing a viable population of Roe Deer in their former habitat. On 19 January 2006, 26 individuals (11 males and 15 females) were released in the reserve. 


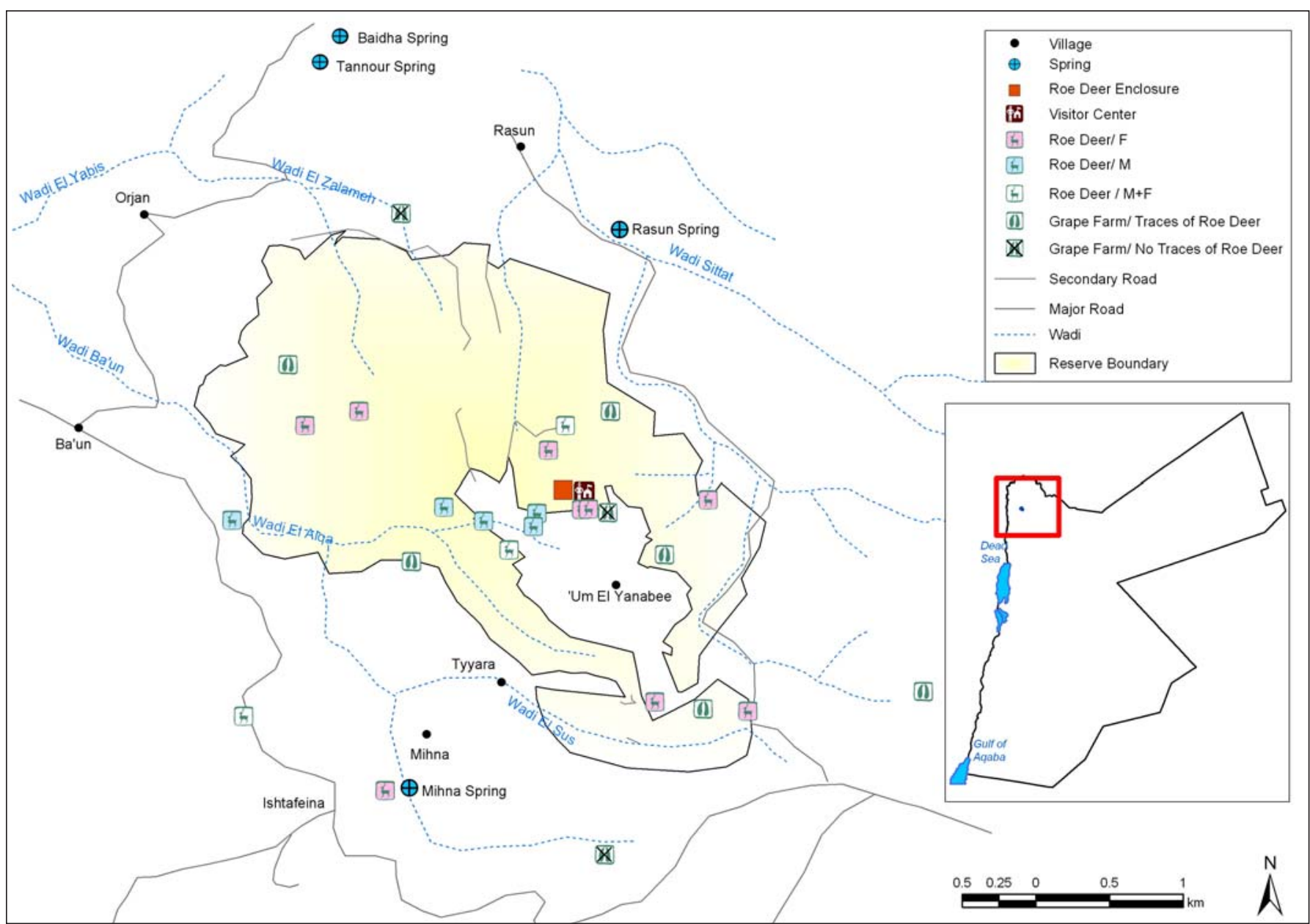

Figure 1. Distribution of the European Roe Deer Capreolus capreolus population at Ajloun Nature Reserve, Jordan, in 2007

\section{Methods}

\section{Study Area}

Ajloun Forest Reserve is located in the northern part of Jordan $\left(35^{\circ} 45^{\prime} 32^{\prime \prime} \mathrm{N} \& 32^{\mathrm{O}_{2}} 2^{\prime} 50^{\prime \prime} \mathrm{E}\right)$, with elevation ranging from 700 to $1050 m$ (RSCN 2005). It was established and managed by the RSCN in 1989 and extends over $12 \mathrm{~km}^{2}$ of mountainous terrain. The reserve is dominated by the Evergreen Oak Quercus calliprinos, which is characterized by a maximum height of $5 \mathrm{~m}$ and classified as Mediterranean shrub (Al-Eisawi 1996). Other associated tree and shrub species include the Palestinian Pistachio Pistacia palaestina, Strawberry tree Arbutus andrachne, Hawthorn Crataegus azarolus, Buckthorn Rhamnus palaestina, and Deciduous Oak Quercus infectoria (AlEisawi 1996).

\section{Survey}

Rapid assessment survey was conducted through August and September 2007 with the aim to draw a basic distribution map, collect data on feeding sources and habits and to assess the effect of releasing the deer at Ajloun Reserve. The team used the global positioning system Garmin V with accuracy of $\pm 5 \mathrm{~m}$, and the following methods were applied

\section{Desktop Survey}

A detailed desk study of past reports and documents from the RSCN sections were performed. This information included data on the breeding and release program.

\section{Field Survey}

A series of targeted visits were conducted through mid August and early September 2007. During these visits, a visual census was undertaken with counts in the early morning and at dusk at the four main water sources and four vantage points. Also, methodical walks (spoor route) to cover areas ranging from dense to low vegetation cover were undertaken. All signs of deer were recorded, particularly accumulated droppings, footprints and deer paths. Observations were obtained from opportunistic sightings of deer at the reserve in addition to observations by rangers and/ or reserve staff. Lastly, local people and private landowners were interviewed in order to learn their views about the program and to obtain some feedback on the released Roe Deer.

\section{Results and Discussion}

No results were obtained from visual censuses due to high disturbance by human activities during summer season around water springs. Additionally, vantage points were not efficient at Ajloun due to the high percentage crown tree density, which estimated by the forest inventory during 2006 of (90\%). The spoor route method showed that the populations had spread both in the reserve and also extended outside of the reserve (Fig. 1). All dropping were found only in areas with low trees 

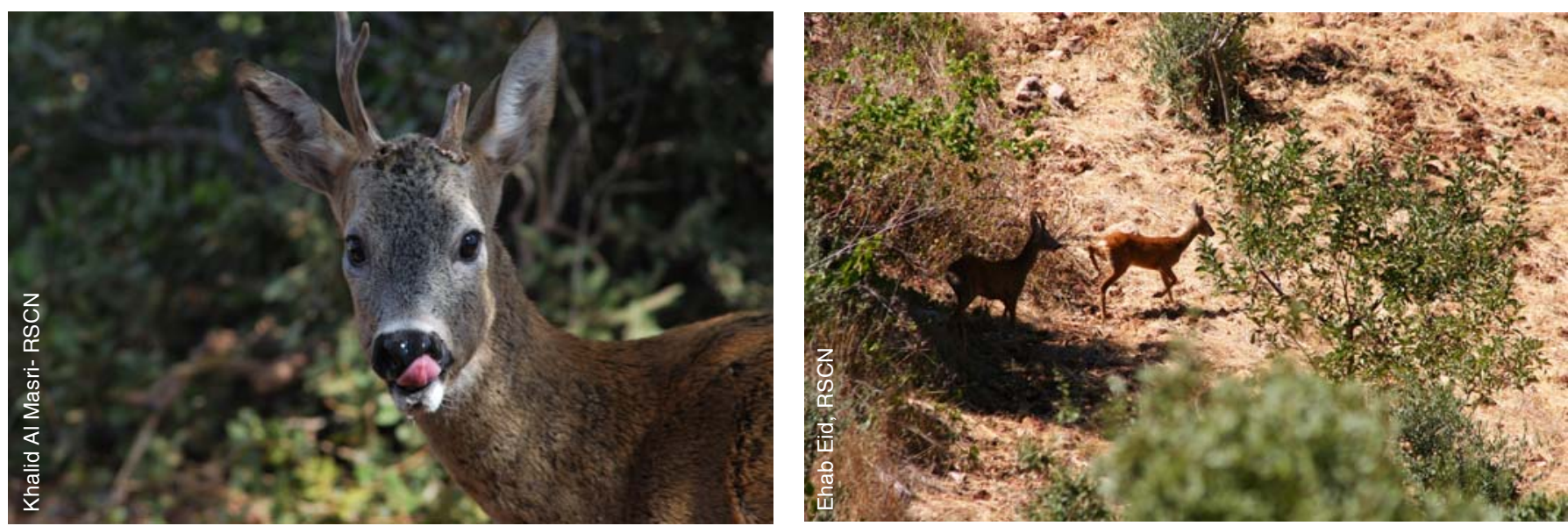

Images 1 \& 2: European Roe Deer Capreolus capreolus after release in the Ajloun Nature Reserve, Jordan

density. This is in accordance to Nowak et al. (1983), who stated that this species avoids thick forest preferring sparsely wooded valleys and the lower slopes of mountains. No attempt was made to systematically count all the deer present, or to use methods such as pellet counts (Mayle 1999). Four different individuals (two males and two females) were observed opportunistically resting in a vineyard located inside the reserve, and mating was recorded during the survey.

Data collected from the opportunistic observations and from interviews indicate that the deer prefer to use vineyard for feeding and resting. The proximity of vineyard inside and around the reserve means an easy, accessible feeding source for the deer at the same time protecting the herd by continuous patrolling activities at the site. It was found that grape leaves are the most palatable food, followed by apple, apricot and olive leaves, the natural diet of deer in the wild. Kjostvedt et al. (1998) reported that the Roe Deer seems to assess risk factors in using agricultural crops for feeding. One of the major threats to the deer population comes from local farmers, who complain about the deer damaging their crops, although the Wild Boar Sus scrofa is responsible for most damage to private land and crops at the Ajloun area.

\section{Assessment of the release program}

Several studies conclud that to increase the success of the re-introduction programs three major factors should be addressed: number of animals released, monitoring and follow up, and the status of the release site (Beck et al. 1991; Allen et al. 1993; Bright \& Morris 1994; Veltman et al. 1996).

The main shortcoming of the release program of Roe Deer at ANR was the little of official records that would have provided valuable information on mortality, behavior, activity, reproductive female status, and death factors during the breeding program. A further disadvantage was the lack of model defining the numbers of years required to establish a viable population and likewise conditions, optimal numbers and status of individuals to be released per year. . Moreover, no detailed study on the effects of the released herd on Ajloun Forest Reserve was performed, especially the effects of Roe Deer on the general biodiversity and habitat composition of the area. Finally, the lack of socio-economic programs has led to several compliance from local people toward the release program.
On the other hand, the RSCN has succeeded in many stages of the re-introduction program. The effective long-term management in the site will contribute to enhancing the conservation of habitat and species and reducing the main causes that led to the extinction of Roe Deer, also conducting several outreach programs targeted at different stakeholders and locals. Periodic patrolling plans are accomplished by the reserve rangers inside and outside the reserve, and by the recent cooperation between the RSCN and the environmental police "Rangers". Lastly, constant monitoring programs, which target habitat and deer population at ANR, will indeed increase the success of the program and conservation measures.

In conclusion, we find that the RSCN has partially succeeded in the re-introduction program since it has managed to establish a viable population living freely in its former natural habitat, under effective long-term management at the site. However, for complete success to be achieved, the following recommendations are made: implementation of a socioeconomic program to stakeholder to increase participation and contribution to the success of the release program. Permanent outreach programs to the local population make aware of the importance of protecting endangered species; to secure continued funding for the program; provide training in deer management for the ecologist and other reserve staff; and to maintain a periodic monitoring program for the released herd.

\section{References}

Al-Eisawi, D. (1996). Vegetation of Jordan. UNESCO- Cairo office. 42pp. Allen, D.H., K.E. Franzreb \& R.E.F. Escano (1993). Efficacy of translocation strategies for red-cockaded woodpeckers. Wildlife Society Bulletin 21: 155-159.

Amr, Z.S. (2000). Jordan Country Study on Biological Diversity, Mammals of Jordan. United Nations Environment Program, Amman, 85pp.

Beck, B.B., D.G. Kleiman, J.M. Dietz, I. Castro, C. Carvalho, A. Martins \& B. Rettberg-Beck (1991). Losses and reproduction in reintroduced golden lion tamarins Leontopithecus rosalia. Dodo 27: 50-61.

Bright, P.W. \& P.A. Morris (1994). Animal translocation for conservation: performance of dormice in relation to release methods, origin and season. Applied Ecology 31: 699-708.

Carruthers, D. (1909). Big Game of Syria, Palestine and Sinia. Field, London. 114: 1135

Harisson, D.L \& P.J.J. Bates (1991). The Mammals of Arabia - 2nd Edition. Harrison Zoological Museum Publication.

Harrison, D.L. (1968). The Mammals of Arabia, Vol. 2: Carnivora, Artiodactyla, Hyracoidea, E. Benn, London, 193-382pp. 
Kjostvedt, J.H., A. Mysterud \& E. Ostbye (1998). Roe Deer; Capreolus capreolus use the agricultural crops during winter in the Lier valley, Norway. Wildlife Biology 4: 23-31

Mayle, B. (1999). Managing deer in the countryside. Forestry Commission Practice Note, 6.

Nowak, R. \& J. Paradiso (1983). Walker's Mammals of the World Vol 22. 4th Edition John Hopkin's University Press, $1226 \mathrm{pp}$.

Qumsiyeh, M.B. (1996). Mammals of the Holy Land. Texas Tech.Univ. Press, Texas, 389pp.

RSCN (2005). Ajloun Forest Reserve Management Plan (unpublished).

Veltman, C.J., S. Nee \& M.J. Crawley (1996). Correlates of introduction success in exotic New Zealand birds. American Naturalist 147: 542-557.
Author Details: Mr. EнAB EID obtained his B.Sc degree in biological science from the University of Jordan in 2001. After his graduation, he worked for three years and a half at the Marine Science Station as a research assistant and engaged in studying the marine wildlife of the Gulf of Aqaba. He then moved to work at the Royal Society for the Conservation of Nature (RSCN) headquarter as fauna research team leader. He is currently involved in the Masters degree program in conservation, access and management of species in trade; the international framework at the International University of Andalucía, Spain. Mr. YASEEN AnANBer completed his B.Sc. Degree in Agricultural Science from Jordan University for Science and Technology. Now he is working at Ajloun Nature Reserve as site ecologist. $\mathrm{He}$ is enrolled in several research programs inside the Reserve. 